\title{
Quantifying the relative importance of transcellular and paracellular ion transports to coral polyp calcification
}

\author{
Sönke Hohn ${ }^{1 *}$ and Agostino Merico ${ }^{1,2}$ \\ ${ }^{1}$ Systems Ecology Group, Theoretical Ecology and Modelling, Leibniz Center for Tropical Marine Ecology, Bremen, Germany \\ 2 Jacobs University, Bremen, Germany
}

\section{Edited by:}

Eric Pieter Achterberg, GEOMAR

Helmholtz Centre for Ocean

Research Kiel, Germany

Reviewed by:

Arvind Singh, GEOMAR Helmholtz

Centre for Ocean Research Kiel,

Germany

Sylvie Mireille Tambutté, Centre

Scientifique de Monaco, Monaco

\section{*Correspondence:}

Sönke Hohn, Systems Ecology

Group, Theoretical Ecology and

Modelling, Leibniz Center for

Tropical Marine Ecology,

Fahrenheitstraße 6, 28359 Bremen,

Germany

e-mail:soenke.hohn@

zmt-bremen.de
Ocean acidification due to rising atmospheric $\mathrm{pCO}_{2}$ slows down coral calcification and impedes reef formation, with deleterious consequences for the diversity of reef ecosystems. Such interactions contrast with the capacity of corals to actively regulate the chemical composition of the calcifying fluid where calcification occurs. This regulation involves the active transport of calcium, bicarbonate, and hydrogen ions through epithelium cells, the transcellular pathway. Ions can also passively diffuse through intercellular spaces via the paracellular pathway, which directly exposes the calcifying fluid to changes in ocean chemistry. Although evidence exists for both pathways, their relative contribution to coral calcification remains unknown. Here we use a mathematical model to test the plausibility of different calcification mechanisms also in relation to ocean acidification. We find that the paracellular pathway generates an efflux of calcium and carbonate from the calcifying fluid, causing a leakage of ions that counteracts the concentration gradients maintained by the transcellular pathway. Increasing ocean acidity exacerbates this carbonate leakage and reduces the ability of corals to accrete calcium carbonate.

Keywords: coral polyp model, ion transport, calcification, biomineralization, numerical simulation, ocean acidification

\section{INTRODUCTION}

Scleractinian corals are sessile, small colonial animals (polyps) that produce skeleton structures of calcium carbonate in the mineral form of aragonite (Cohen and McConnaughey, 2003; Allemand et al., 2011; Tambutté et al., 2011). Over millions of years, these organisms form large amounts of carbonate rocks and calcareous sediments, the reefs, hosting one of the richest, and most diverse ecosystems of our planet (Kleypas et al., 2001). Coral reefs are important carbon stores albeit accretion of calcium carbonate (calcification) changes the equilibrium of the seawater carbonate system by removing alkalinity, thus releasing $\mathrm{CO}_{2}$ into the atmosphere (Ware et al., 1992; Frankignoulle et al., 1994). Coral calcification is therefore a key process in the global carbon cycle (Hallock, 1997).

Coral polyps cover their skeleton with at least four layers of organic tissue, which separate the calcifying fluid (i.e., the space where the skeleton is formed) from seawater (Allemand et al., 2011). Calcium and carbonate ions, the building blocks of the coral skeleton, have to be constantly supplied to the calcifying fluid to sustain coral calcification (Hohn and Merico, 2012). It is generally agreed that calcium ions are transported via a combination of calcium channels and an active calcium pump (Ca-ATPase) (Ip et al., 1991; Zoccola et al., 1999, 2004; Cohen and McConnaughey, 2003; Allemand et al., 2004), which transports two calcium ions in exchange of two to four protons across the cell membrane (Inesi, 1985; Gould et al., 1986; Allemand et al., 2004; Winther et al., 2013) under consumption of metabolic energy (ATP). Carbon can cross the coral cells via free diffusion of $\mathrm{CO}_{2}$ over cell membranes (Sueltemeyer and Rinast, 1996) or as bicarbonate via a bicarbonate transporter (Furla et al., 2000; Vidal-Dupiol et al., 2013). This route is called the transcellular pathway because calcium and carbon have to pass through the cytoplasm of the coral cells. Although a bicarbonate transporter has been sequenced in a coral transcriptome, there is no transporter known for carbonate. Once $\mathrm{CO}_{2}$ or bicarbonate reaches the calcifying fluid, a new chemical equilibrium between $\mathrm{CO}_{2}$, bicarbonate and carbonate is established (Zeebe and WolfGladrow, 2001). Thus, carbonate ions in the calcifying fluid can be resupplied via transport of any other carbon species (Hohn and Merico, 2012).

Experiments with a membrane impermeable dye (calcein), however, suggest that seawater may also enter the calcifying fluid directly, i.e., without transiting the cytoplasm (Cuif et al., 2011; Tambutté et al., 2011, 2012; Gagnon et al., 2012). This alternative transport mechanism has been called the paracellular pathway. The paracellular pathway either works as a diffusive or advective flux and exchanges all dissolved ions between seawater and the calcifying fluid (Cohen and McConnaughey, 2003; Gagnon et al., 2012; Nakamura et al., 2013). To which extent the transcellular and paracellular pathway contribute to the overall calcium and carbon fluxes is, however, largely unknown (Tambutté et al., 2011, 2012). 
Mathematical models represent ideal tools for quantifying such processes. Although a number of mathematical models for coral calcification have already been developed (Ries, 2011; Gagnon et al., 2012; Hohn and Merico, 2012; Nakamura et al., 2013), each with different characteristics, none of these studies have adequately quantified the relative contribution of the transcellular and paracellular pathways to coral calcification. Our earlier study (Hohn and Merico, 2012), for example, focused exclusively on the transcellular ion transport and thus could not explain the results obtained with calcein staining experiments. Gagnon et al. (2012) assumed a ratio of active ion pumping to precipitation of $10 \%$ and imposed a priori a very strong relative importance $(90 \%)$ of the paracellular pathway over the ion exchange between the calcifying fluid and seawater. Nakamura et al. (2013), instead, focused on the simulation of the mechanisms leading to light-enhanced calcification but did not quantify the ion fluxes. Ries (2011) investigated the $\mathrm{pCO}_{2}$ dependence of calcification rates on different proton pumping intensities but assumed fixed calcium concentrations in the calcifying fluid and no dynamic transport.

In the present study, we extend our earlier calcification model (Hohn and Merico, 2012) to test four different hypotheses that reflect alternative realizations of ion transport in corals. The hypotheses are: H1, coral calcification is induced only by transcellular ion transport of calcium and bicarbonate into the calcifying fluid as proposed by Allemand et al. (2004), see their Figure 2A; H2, only the paracellular pathway supplies calcium and carbon for coral calcification as proposed by Gagnon et al. (2012); H3, a proton pump removes protons from the calcifying fluid to increase aragonite saturation while calcium enters the calcifying fluid passively via the paracellular pathway, also known as the proton flux hypothesis (Jokiel, 2011; Ries, 2011); and H4, coral calcification is induced by a combination of transcellular and paracellular ion transport (Cohen and McConnaughey, 2003; Nakamura et al., 2013) (Figure 1).

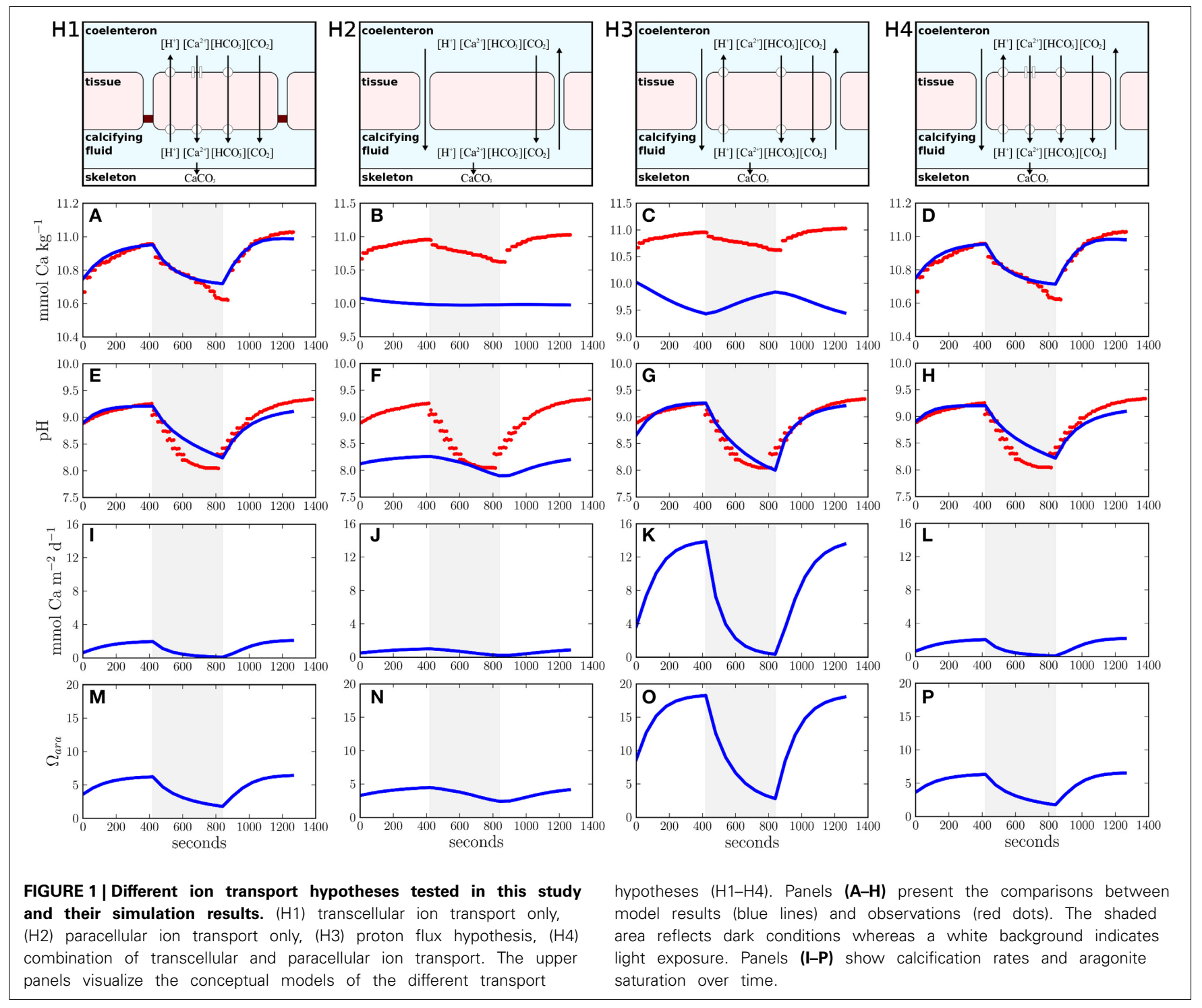




\section{MATERIALS AND METHODS \\ 2.1. MODEL DESCRIPTION}

Our study used a coral polyp model that simulates the temporal evolution of the full carbonate chemistry kinetics in four different compartments: the seawater, the polyp tissue, the coelenteron (coral stomach), and the calcifying fluid (Hohn and Merico, 2012). Ion transport fluxes dynamically connect the different model compartments and $\mathrm{CO}_{2}$ is allowed to diffuse freely across the compartment boundaries (membranes). The most sensitive model parameters within the four hypotheses (given in Table 1) are systematically varied by an optimization algorithm (see below) to best fit the only available observations to date of the time evolution of calcium and $\mathrm{pH}$ in the calcifying fluid of the scleractinian coral Galaxea fascicularis (Al-Horani et al., 2003). These observations present a unique and powerful constraint for modeling coral calcification because they were obtained using micro-electrodes inserted into the calcifying fluid, just beneath the coral tissue, under fluctuating light-dark conditions. The model produces a full suite of time series, including $\mathrm{CO}_{2}, \mathrm{HCO}_{3}^{-}, \mathrm{CO}_{3}^{2-}, \mathrm{H}^{+}, \mathrm{OH}^{-}, \mathrm{B}(\mathrm{OH})_{3}, \mathrm{~B}(\mathrm{OH})_{4}^{-}$, and $\mathrm{Ca}^{2+}$ (see Supplementary Figures 1-4). In Figure 1, we present the variables best compared to the available observations: $\left[\mathrm{Ca}^{2+}\right]$ and $\mathrm{pH}$ in the calcifying fluid.

The model is numerically solved over a time period of $1260 \mathrm{~s}$ following:

$$
\begin{aligned}
y(t) & =\vec{v}(t) \\
y^{\prime}(t) & =\vec{f}(t) \\
\vec{f}(t) & =\mathbf{M} \times \vec{r}(t)
\end{aligned}
$$

where $\vec{v}(t)$ represents the array of state variables, $\vec{f}(t)$ represents the flux array, that is defined by the product of the reaction array, $\vec{r}(t)$, and the flux matrix, $\mathbf{M}$. The flux matrix $\mathbf{M}$ assigns all single reactions defined in $\vec{r}(t)$ to concentration changes of the state variables $\vec{v}(t)$ under consideration of the different volumes of the model compartments.

The state variables $\vec{v}$ represent the concentrations of $\mathrm{CO}_{2}$, $\mathrm{HCO}_{3}^{-}, \mathrm{CO}_{3}^{2-}, \mathrm{H}^{+}, \mathrm{OH}^{-}, \mathrm{B}(\mathrm{OH})_{3}, \mathrm{~B}(\mathrm{OH})_{4}^{-}$, and $\mathrm{Ca}^{2+}$ in the four model compartments (seawater, tissue, coelenteron, and calcifying fluid, as indicated by the subscripts sea, tiss, coel, and calc, respectively). The processes that are calculated in the reaction array $\vec{r}$ are the full kinetic reactions of the carbonate chemistry in the four model compartments (56 reactions in total, $r_{(1: 56)}$ ), the advective exchange of the state variables between the coelenteron and seawater $\left(r_{(57: 64)}\right)$, diffusive $\mathrm{CO}_{2}$ exchange over the cell membranes of tissue cells with the seawater, the coelenteron, and the calcifying fluid $\left(r_{(65: 67)}\right)$, active transport of carbon $\left(r_{(68: 70)}\right)$ and calcium $\left(r_{(71: 73)}\right)$ as well as protons $\left(r_{(74)}\right)$ over the cell membranes, respiration and photosynthesis $\left(r_{(75: 76)}\right)$, and finally the precipitation of calcium carbonate into the coral skeleton $\left(r_{(77)}\right)$. The model and the considered reactions are fully detailed in the original article (Hohn and Merico, 2012). However, since the original model did not account for the paracellular ion transport, we expanded the model equations to account for an advective flux that exchanges dissolved ions between the coelenteron and the calcifying fluid through the intercellular space. The new equations are:

$$
r_{(78: 85)}=\left[\begin{array}{c}
\psi \cdot\left(\mathrm{CO}_{2 \text { (coel) }}-\mathrm{CO}_{2(\text { calc })}\right) \\
\psi \cdot\left(\mathrm{HCO}_{3 \text { (coel) }}^{-}-\mathrm{HCO}_{3(\text { calc })}^{-}\right) \\
\psi \cdot\left(\mathrm{CO}_{3(\text { coel })}^{2-}-\mathrm{CO}_{3(\text { calc })}^{2-}\right) \\
\psi \cdot\left(\mathrm{H}_{(\text {coel })}^{+}-\mathrm{H}_{(\text {calc })}^{+}\right) \\
\psi \cdot\left(\mathrm{OH}_{(\text {coel })}^{-}-\mathrm{OH}_{(\text {calc })}^{-}\right) \\
\psi \cdot\left(\mathrm{B}(\mathrm{OH})_{3(\text { coel })}-\mathrm{B}(\mathrm{OH})_{3(\text { calc })}\right) \\
\psi \cdot\left(\mathrm{B}(\mathrm{OH})_{4(\text { coel })}^{-}-\mathrm{B}(\mathrm{OH})_{4(\text { calc })}^{-}\right) \\
\psi \cdot\left(\mathrm{Ca}_{(\text {coel })}^{2+}-\mathrm{Ca}_{(\text {calc })}^{2+}\right)
\end{array}\right]
$$

The array $\vec{r}$ now contains 85 equations for the individual fluxes, while the fluxes $78-85\left(r_{(78: 85)}\right)$ represent the paracellular pathway. The inclusion of this process adds only one additional unknown parameter to the model, the exchange rate of the paracellular transport, $\psi$, leading to a maximum of five parameters that were optimized simultaneously in the parameter optimization process. These unknown parameters were the calcium as well as the bicarbonate transport rate via transcellular ion transport, the photosynthesis and respiration rates and the exchange rate of the paracellular transport. According to the hypothesis tested, the transcellular and paracellular fluxes were switched on and off by setting the parameter values to zero. All other model parameters were left unchanged.

\subsection{PARAMETER OPTIMIZATION}

For each tested hypothesis $(\mathrm{H} 1-\mathrm{H} 4)$, we use the optimization algorithm fmin from the open source scipy.optimize software package to find the best fitting model solution to the data of Al-Horani et al. (2003). The applied algorithm systematically varies the unknown model parameters and runs the model several hundreds or thousands of times until a minimum of the costfunction, $I$, is found. The costfunction $I$ is defined as the sum

Table 1 | Parameter values as a result of the model optimization for hypotheses H1-H4.

\begin{tabular}{lccccc}
\hline Parameter (variable) & H1 & H2 & H3 & H4 & Unit \\
\hline $\mathrm{Ca}^{2+}$ transport rate & $7.05 \mathrm{e}^{-12}$ & - & - & $7.28 \mathrm{e}^{-12}$ & $\mathrm{~mol} \mathrm{polyp}^{-1} \mathrm{~s}^{-1}$ \\
$\mathrm{H}^{+}$transport rate & $14.09 \mathrm{e}^{-12}$ & - & $38.90 \mathrm{e}^{-12}$ & $14.57 \mathrm{e}^{-12}$ & $\mathrm{~mol} \mathrm{polyp}^{-1} \mathrm{~s}^{-1}$ \\
$\mathrm{HCO}_{3}^{-}$transport rate & $3.56 \mathrm{e}^{-15}$ & - & $0.97 \mathrm{e}^{-15}$ & $1.15 \mathrm{e}^{-15}$ & $\mathrm{~mol} \mathrm{polyp}^{-1} \mathrm{~s}^{-1}$ \\
Photosynthesis rate & $1.65 \mathrm{e}^{-08}$ & $19.65 \mathrm{e}^{-08}$ & $12.83 \mathrm{e}^{-8}$ & $1.25 \mathrm{e}^{-08}$ & $\mathrm{~mol} \mathrm{polyp}^{-1} \mathrm{~s}^{-1}$ \\
Respiration rate & $5.11 \mathrm{e}^{-08}$ & $51.51 \mathrm{e}^{-08}$ & $7.81 \mathrm{e}^{-8}$ & $5.72 \mathrm{e}^{-08}$ & $\mathrm{~mol} \mathrm{polyp}$ \\
Paracellular transport rate & - & $8.39 \mathrm{e}^{-03}$ & $5.33 \mathrm{e}^{-4}$ & $1.28 \mathrm{e}^{-11}$ & $\mathrm{~mol} \mathrm{polyp}^{-1} \mathrm{~s}^{-1}$
\end{tabular}


of the individual costfunctions for calcium concentrations, $I_{\mathrm{Ca}}$, and $\mathrm{pH}, I_{\mathrm{pH}}$ (Equation 7). The individual costfunctions for calcium and $\mathrm{pH}$ are calculated as the sum of the deviation between the model and the data at any given timestep squared. The difference between model and data is divided by the amplitude of the observed calcium or $\mathrm{pH}$ signal, $A_{\mathrm{Ca}}$ and $A_{p \mathrm{H}}$, respectively (Equations 5, 6), to avoid different weighing of the individual datasets in the combined costfunction $I$ (Equation 7). Since this normalization leads to values between 0 and 1 , we multiply this value by 1000 to improve the performance of the optimization routine which works better with larger numbers. The calculated sum is then normalized by the number of considered data, $n_{\mathrm{Ca}}$ or $n_{p \mathrm{H}}$, to account for the length of the compared datasets.

$$
\begin{aligned}
I_{\mathrm{Ca}} & =\sum_{i=1}^{n_{\mathrm{Ca}}}\left(\frac{\mathrm{Ca}_{\text {model }(i)}-\mathrm{Ca}_{\text {data }(i)}}{A_{\mathrm{Ca}}} \cdot 1000\right)^{2} \cdot \frac{1}{n_{\mathrm{Ca}}} \\
I_{p \mathrm{H}} & =\sum_{i=1}^{n_{p \mathrm{H}}}\left(\frac{p \mathrm{H}_{\text {model }(i)}-p \mathrm{H}_{\text {data }(i)}}{A_{p \mathrm{H}}} \cdot 1000\right)^{2} \cdot \frac{1}{n_{p \mathrm{H}}} \\
I & =I_{\mathrm{Ca}}+I_{p \mathrm{H}}
\end{aligned}
$$

The amplitude of the observed signals is calculated as the difference between maximum and minimum data, as follows:

$$
\begin{aligned}
& A_{\mathrm{Ca}}=\max \left(\mathrm{Ca}_{\text {data }}\right)-\min \left(\mathrm{Ca}_{\text {data }}\right) \\
& A_{p \mathrm{H}}=\max \left(p \mathrm{H}_{\text {data }}\right)-\min \left(p \mathrm{H}_{\text {data }}\right)
\end{aligned}
$$

\subsection{SENSITIVITY AND $\mathrm{pCO}_{2}$ DEPENDENCE}

Under scenario H4, we performed a sensitivity analysis by progressively increasing the exchange rate of the paracellular transport by factors of $1,10,100,1000$, and 10,000, while keeping all other parameters fixed. To analyse the dependence of coral calcification on ambient $\mathrm{pCO}_{2}$, we changed the $\mathrm{pCO}_{2}$ in the seawater gradually from 400 to $800 \mathrm{ppmv}$ and repeated the simulations with all four hypotheses and under constant light conditions. To account for the uncertainty in the optimized parameter values, we also varied the calcium transport rate $(\mathrm{H} 1+\mathrm{H} 4)$, the paracellular exchange rate $(\mathrm{H} 2)$ and the proton transport rate $(\mathrm{H} 3)$ by $\pm 25 \%$.

\section{RESULTS}

\subsection{ION TRANSPORT HYPOTHESES}

Simulations compare favorably with the observations (Figures 1A,E) when the transcellular pathway is assumed to be the only mechanism for ion transport (H1) (Allemand et al., 2004; Hohn and Merico, 2012). In this case, calcium concentrations in the calcifying fluid increase in the light due to the activity of the Ca-ATPase. In the dark, calcium concentrations decrease due to aragonite precipitation. For every calcium ion transported by the Ca-ATPase, two protons are removed from the calcifying fluid thus increasing $\mathrm{pH}$ in the light regime. In the dark, active ion transport ceases and calcifying fluid $\mathrm{pH}$ decreases due to the removal of alkalinity via aragonite precipitation. Additionally, the release of $\mathrm{CO}_{2}$ via coral respiration in the dark and its consumption via photosynthesis in the light contribute to the variation of $\mathrm{pH}$ in the calcifying fluid (Figure 1E). The assumption of no direct connection between seawater and the calcifying fluid is, however, inconsistent with observations showing the incorporation of the membrane impermeable dye calcein into the coral skeletons (Tambutté et al., 2011, 2012; Gagnon et al., 2012). Therefore, despite the good agreement with the observations, $\mathrm{H} 1$ must be rejected.

$\mathrm{H} 2$, that is when only the paracellular pathway supplies calcium and carbon to the calcifying fluid, fails to explain the observations (Figures 1B,F) because, in this case, the observed concentration gradients between the calcifying fluid and seawater cannot be established. The paracellular pathway leads to an equilibration of $\mathrm{pH}$ and calcium ion concentration between the calcifying fluid and seawater. Consumption and release of $\mathrm{CO}_{2}$ via photosynthesis and respiration are the only processes affecting $\mathrm{pH}$ in the calcifying fluid (Figure 1F). As suggested by our flux budget calculations (Table 2), metabolic $\mathrm{CO}_{2}$ diffuses into the calcifying fluid and leaks into seawater via the paracellular pathway. The influence of this metabolic $\mathrm{CO}_{2}$ on the carbonate equilibrium creates a slight decrease in the $\mathrm{pH}$ of the calcifying fluid and, consequently, an export of protons and boric acid into seawater, while bicarbonate, carbonate, hydroxide ions, borate, and calcium leak in. Although $\mathrm{H} 2$ is consistent with calcein staining experiments, it does not allow any active regulation of the calcifying fluid composition, except for some minor changes in $\mathrm{pH}$ due to respiration and photosynthesis by the coral holobiont. This hypothesis is thus unable to explain the observed changes in calcium ion concentrations in the calcifying fluid with changing light conditions. In addition, the changes in $\mathrm{pH}$ resulting from the simulation of this hypothesis are inconsistent with the observations. Therefore, we reject also $\mathrm{H} 2$.

The simulation of $\mathrm{H} 3$ leads to good agreement with the $\mathrm{pH}$ measured in the calcifying fluid (Figure 1G). However, the removal of protons from the calcifying fluid increases the aragonite saturation state (Figure 10) thus favoring the precipitation of aragonite (Figure 1K). The enhanced activity of the proton pump during light exposure therefore leads to a decrease of calcium concentrations in the calcifying fluid. When the activity of the proton pump declines in the dark, calcium concentrations are resupplied via the paracellular pathway. These fluctuations of calcium concentrations in the calcifying fluid under light and dark conditions are opposite to the observations (Figure 1C), we therefore reject also this hypothesis.

The concomitant activation of the transcellular and paracellular pathways in the model (H4) leads to results consistent with the available observations (Figures $\mathbf{1 D}, \mathbf{H}$ ). The least squared deviation between simulated and observed results, i.e., a quantitative measure of the difference between the model results and the data, is also slightly smaller for $\mathrm{H} 4(I=22,191.2)$ than for $\mathrm{H} 1$ $(I=22,419.3)$, see Supplementary Table 1 . The ion flux budget for $\mathrm{H} 4$ reveals that the paracellular pathway acts as a loss of calcium, carbonate, hydroxide, and borate ions from the calcifying fluid and as a source of carbon dioxide, bicarbonate, protons, and boric acid (Table 2). The model solution for $\mathrm{H} 4$ suggests that the paracellular pathway contributes rather little to the total $\mathrm{CO}_{2}$ fluxes, $1.26 \mathrm{mmol} \mathrm{m}^{-2} \mathrm{~d}^{-1}$ transcellular flux vs. $0.02 \mu \mathrm{mol} \mathrm{m}{ }^{-2} \mathrm{~d}^{-1}$ paracellular flux, whereas it contributes more substantially to the transport of bicarbonate, $0.1 \mu \mathrm{mol} \mathrm{m} \mathrm{m}^{-2} \mathrm{~d}^{-1}$ transcellular flux 
vs. $16.3 \mu \mathrm{mol} \mathrm{m}{ }^{-2} \mathrm{~d}^{-1}$ paracellular flux. The loss of calcium ions through the paracellular passage is low compared to the transcellular ion transport (Figure 2).

From the absolute ion fluxes (Table 2), we calculate the relative contribution of the transcellular and paracellular pathway as the relative fraction of each pathway to the sum of both. While the transcellular calcium flux is represented by the activity of the Ca-ATPase, the transcellular flux of carbon is represented by the sum of active bicarbonate transport and $\mathrm{CO}_{2}$-diffusion between the calcifying fluid and the coral tissue. The paracellular flux for calcium is described by reaction $r_{(85)}$ only, while the paracellular flux of carbon is calculated from the combined exchange of $\mathrm{CO}_{2}$, bicarbonate and carbonate $\left(r_{(78: 80)}\right)$. Since the paracellular calcium transport is directed outwards of the calcifying fluid and the sum of transcellular and paracellular calcium flux are supposed to equal $100 \%$, the transcellular calcium transport accounts for $100.8 \%$ while $0.8 \%$ is lost via the paracellular passage. In the case of carbon, the absolute ion fluxes also indicate a loss of carbonate ions from the calcifying fluid (Table 2) but the net carbon flux of the paracellular pathway is directed into the calcifying fluid due to the higher contribution of bicarbonate. In summary, 98.8\% of carbon enters the calcifying fluid via $\mathrm{CO}_{2}$-diffusion or active bicarbonate transport, i.e., the transcellular pathway, while $1.2 \%$ of total carbon enters the calcifying fluid via the paracellular pathway (Figure 2).

\subsection{ENERGY REQUIREMENTS OF CALCIFICATION}

Using the ion flux budgets from the optimized model solutions (Table 2), we can calculate the energetic costs of coral calcification more precisely than by calculating the Nernst potential from the established ion gradients (e.g., Ries, 2011). To translate the ion fluxes into metabolic energy consumption, we assume a $\mathrm{Ca}^{2+}: \mathrm{H}^{+}$:ATP stoichiometry of 2:4:1 for the Ca-ATPase (Inesi, 1985; Allemand et al., 2004; Winther et al., 2013), a $\mathrm{H}^{+}$:ATP stoichiometry of 4:1 for the proton pump (Bennett and Spanswick, 1984; Fillingame, 1997), and a $\mathrm{HCO}_{3}^{-}: \mathrm{H}^{+}$:ATP stoichiometry of 1:1:1 for the bicarbonate transporter. Diffusion

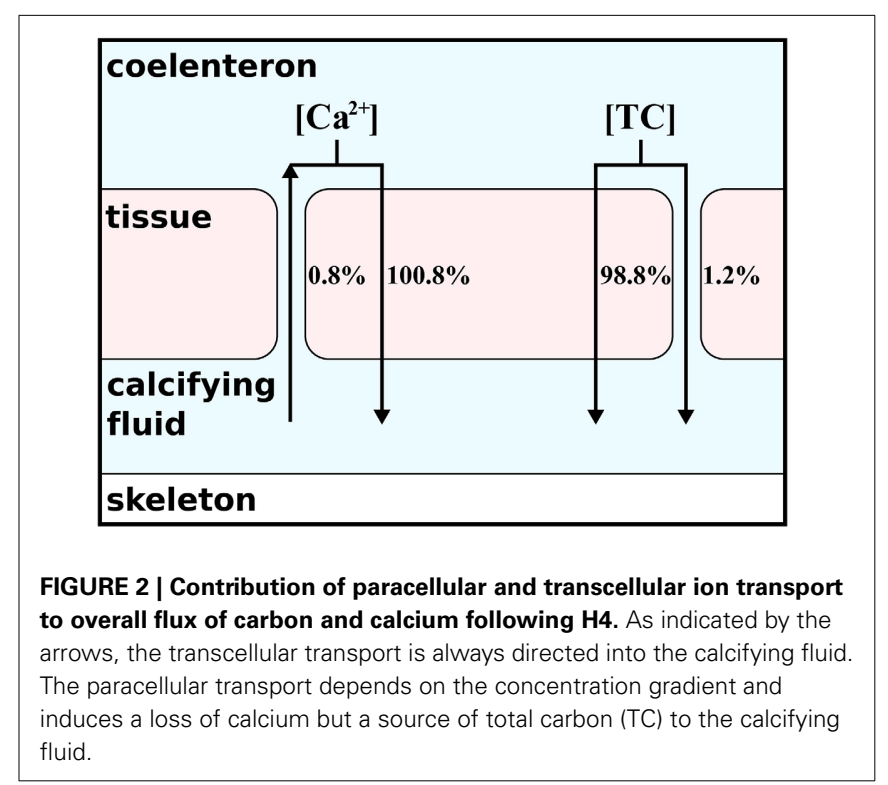

Table 2 | Transport budgets of ions and molecules into the calcifying fluid for the different hypotheses (H1-H4).

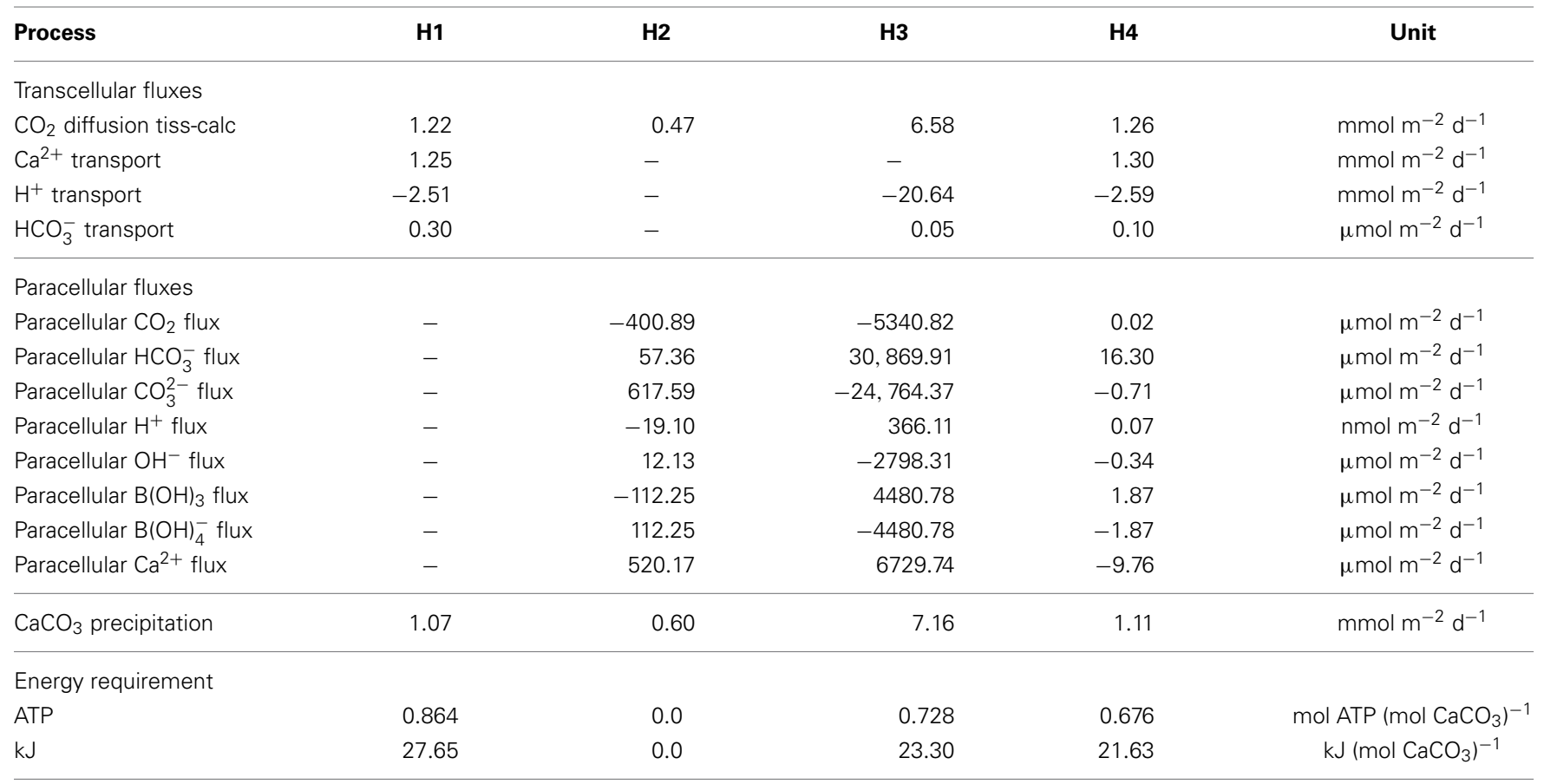

Positive numbers indicate a source to the calcifying fluid, negative values represent a loss from the calcifying fluid. No value means that the process was not considered in the hypothesis. 
of $\mathrm{CO}_{2}$ and the paracellular pathway obviously operate without costs. The Gibbs energy released by hydrolysis of ATP is conservatively estimated around $30 \mathrm{~kJ} \mathrm{~mol}^{-1}$ (Lemasters, 1984) (but see Kamerlin and Warshel, 2009; Bergman et al., 2010). The energetic costs of coral calcification thus result in $0.86,0.0$, $0.73,0.68 \mathrm{~mol} \mathrm{ATP}\left(\mathrm{mol} \mathrm{CaCO}_{3}\right)^{-1}$ or $27.65,0.0,23.30$, and $21.63 \mathrm{~kJ}\left(\mathrm{~mol} \mathrm{CaCO}_{3}\right)^{-1}$ for $\mathrm{H} 1, \mathrm{H} 2, \mathrm{H} 3$, and $\mathrm{H} 4$, respectively (Table 2).

\subsection{SENSITIVITY ANALYSIS}

The optimized ion fluxes calculated under H4 (Table 2) contrast with previous estimates of the relative importance of the paracellular pathway (Gagnon et al., 2012) and also the direction of the calcium flux via this passage is opposite to what was previously proposed (Tambutté et al., 2011, 2012). Therefore, to analyse the relative importance of the paracellular pathway in more detail, we performed a sensitivity analysis with respect to changes in the paracellular exchange rate. Increasing the exchange rate of the paracellular pathway leads to an increasing misfit between model results and observations as calcium leaks out of the calcifying fluid and calcium concentrations approach the seawater background level of $10 \mathrm{mmol} \mathrm{kg}^{-1}$ (Figure 3A). This leakage also allows protons to enter the calcifying fluid, thus equilibrating the $\mathrm{pH}$ towards the seawater value of 8.2 (Figure 3B). Although the activity of the transcellular ion transport as well as photosynthesis and respiration influence the composition of the calcifying fluid, our results show that this impact is outweighed by the increasing influence of the paracellular pathway.

\section{4. $\mathrm{pCO}_{2}$ DEPENDENCE}

In order to test the different calcification hypotheses also in relation to ocean acidification, we ran the model at different $\mathrm{pCO}_{2}$ in the seawater. $\mathrm{H} 1$ and $\mathrm{H} 4$ show both a slight decrease in calcification rates with increasing $\mathrm{pCO}_{2}$ (Figures 4A,D). H2 shows lower calcification rates but a similar decrease at increasing $\mathrm{pCO}_{2}$ with respect to $\mathrm{H} 1$ and $\mathrm{H} 4$ (Figure 4B). H3 produces the highest calcification rates of all cases (one order of magnitude higher) due to relatively high concentrations of total alkalinity and dissolved inorganic carbon in the calcifying fluid and, consistently with Ries (2011), shows an increase of calcification with increasing $\mathrm{pCO}_{2}$ (Figure 4C).

\section{DISCUSSION}

The combination of processes considered in $\mathrm{H} 1$ and $\mathrm{H} 2$, presented here as $\mathrm{H} 4$, is consistent with changes in calcifying fluid $\mathrm{pH}$ and calcium concentrations and with calcein staining experiments. Although simulations with the transcellular transport (H1) match well the observed temporal changes in calcifying fluid $\mathrm{pH}$ and calcium concentrations, as we also showed in an earlier study (Hohn and Merico, 2012), this mechanism alone cannot explain the incorporation of calcein into the growing skeleton as reported in recent studies (Gagnon et al., 2012; Tambutté et al., 2012). Given also the lower model-data least squared deviation obtained with H4 $(I=22,191.2)$ as compared to H1 $(I=22,419.3)$, we consider the combination of transcellular and paracellular ion transport as the most likely mechanism for coral calcification. Besides its capability to explain the observations, we favor $\mathrm{H} 4$ also on the basis of energetic arguments, because the combination of transcellular and paracellular ion transport requires less energy to precipitate $1 \mathrm{~mol}$ of aragonite as compared to all other cases (Table 2). These low energetic costs result from the passive supply of DIC to the calcifying fluid via the paracellular pathway that apparently help saving more energy than what is required to compensate for the consequent leakage of calcium and protons. Given that this pathway does not need the evolution of special physiology or anatomy and consumes less metabolic energy, it is also favored by evolutionary reasoning. The fact that $\mathrm{H} 1$ explains the changes in $\mathrm{pH}$ and calcium concentrations measured in the calcifying fluid almost equally well as $\mathrm{H} 4$ suggests that the paracellular pathway is of minor importance for coral calcification. Indeed, the exchange rate of the paracellular pathway in $\mathrm{H} 4$ as predicted by the model optimization is fairly low. We conclude that the combined transcellular and paracellular transport $(\mathrm{H} 4)$ is the mechanism most compatible
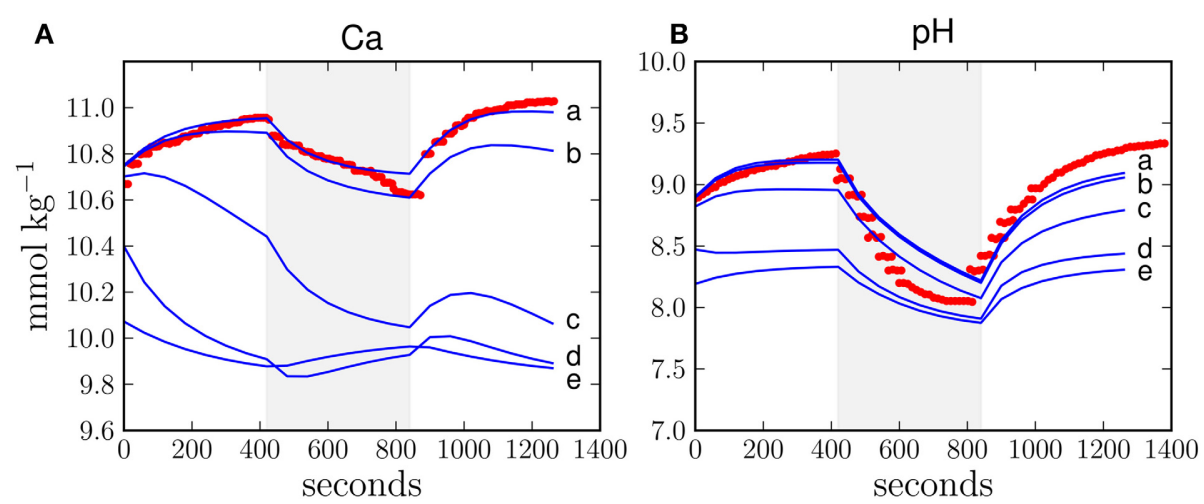

FIGURE 3 | Sensitivity study with respect to the exchange rate of the paracellular pathway in $\mathrm{H} 4$ for calcium concentration (A) and $\mathrm{pH}(B)$ in the calcifying fluid. The exchange rate of the paracellular pathway (Table 1) was multiplied by $1,10,100,1000$, and 10,000 (lines a, b, c, d,

e, respectively). The higher the exchange rate, the larger the deviation between the model results (blue line) and observations (red dots). The shaded area reflects dark conditions and the white background indicates light exposure. 

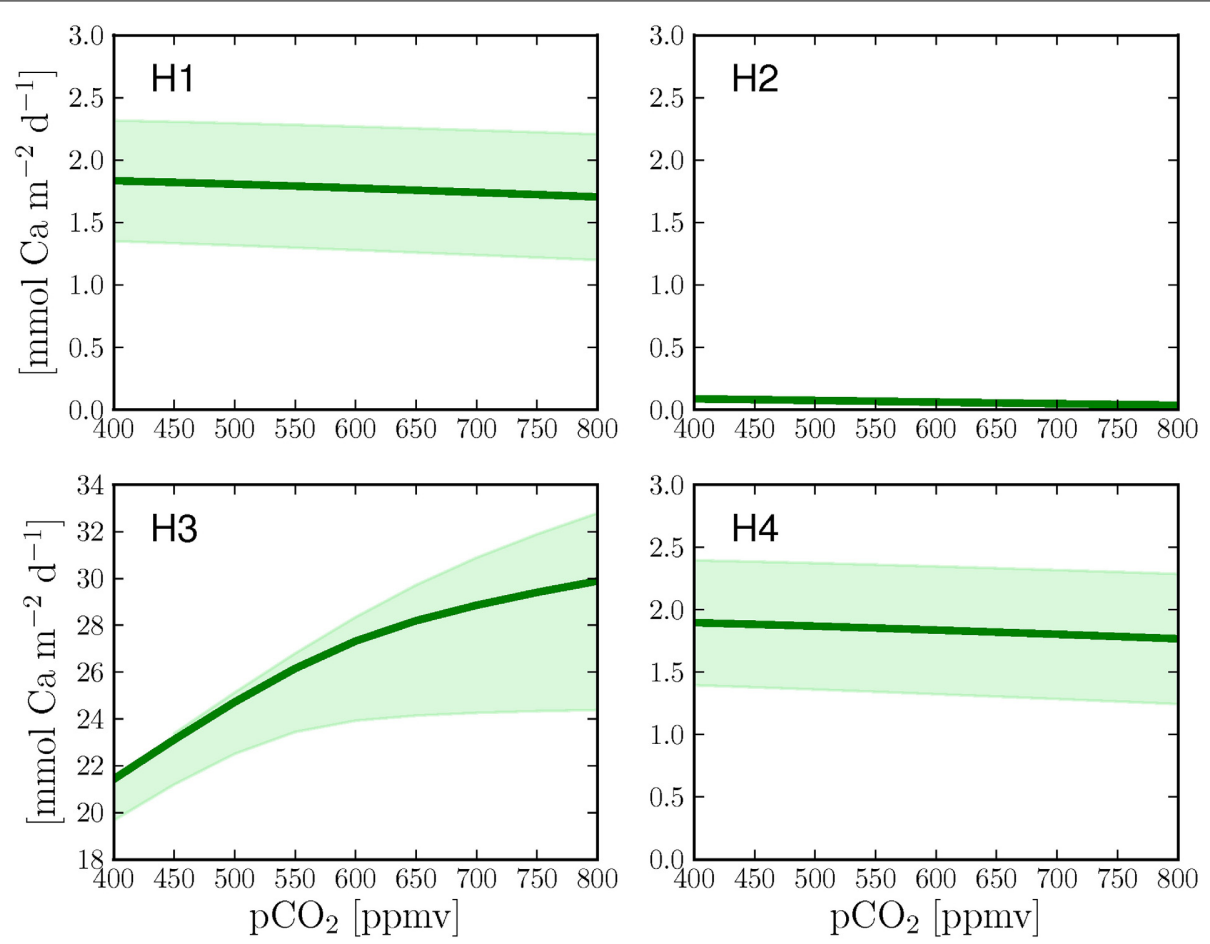

FIGURE 4 | Calcification response of the four hypotheses to increasing $\mathbf{p C O}_{2}$ under continuous light. The graphs also present the changes in calcification rates when the calcium transport rate $(\mathbf{H} \mathbf{1}+\mathbf{H} \mathbf{4})$, the paracellular exchange rate $\mathbf{( H 2 )}$ or the proton transport rate $\mathbf{( H 3 )}$ are changed by $\pm 25 \%$ (shaded area) with respect to the optimized parameter values (Table 1, dark green line). with the available observations, although the paracellular pathway appears to play a minor role for the total calcium and carbon fluxes.

Our finding contrasts with previous model estimates (constrained by deep sea coral data), which suggested a relatively large contribution of the paracellular pathway to coral calcification (Gagnon et al., 2012). These calculations, however, did not account for the observed calcium gradient between seawater and the calcifying fluid. Direct observations of the calcifying fluid (Al-Horani et al., 2003) indicate that the concentration of calcium is about $10.6 \mathrm{mM}$, that is $0.6 \mathrm{mM}$ higher than in seawater $(10.0 \mathrm{mM})$. These numbers may intuitively suggest a negligible contribution of the active ion transport (5.6\%) as only $0.6 \mathrm{mM}$ calcium need to be added to the $10.0 \mathrm{mM}$ from seawater. However, this suggestion implies an initial calcium concentration of $0.0 \mathrm{mM}$, a condition that can only occur in newly settled larvae, which initiate calcification for the first time. The older the coral grows, the smaller the initial contribution from seawater becomes so that adult corals face rather the problem of maintaining elevated calcium and $\mathrm{pH}$ in the calcifying fluid with respect to seawater. Such conditions can be achieved only if the paracellular transport is very small. This can be demonstrated by a steadystate model calculation of calcium fluxes in the calcifying fluid (Gagnon et al., 2012):

$$
\frac{d}{d \mathrm{t}} \mathrm{Ca}_{c f}=F-P+k \cdot\left(\mathrm{Ca}_{s w}-\mathrm{Ca}_{c f}\right)
$$

where $F$ is the flux according to active calcium transport, $P$ is the precipitation into the skeleton, and $k$ is the transport rate of the paracellular pathway that exchanges calcium ions between seawater, $\mathrm{Ca}_{s w}$, and the calcifying fluid, $\mathrm{Ca}_{c f}$. In steady-state, the calcium concentration in the calcifying fluid is constant and the rate of change, $\frac{d}{d t} \mathrm{Ca}_{c f}$, equals zero. The elevated calcium concentrations in the calcifying fluid $(10.6 \mathrm{mM})$ with respect to seawater (10.0 mM) (Al-Horani et al., 2003), produces a negative gradient $\left(\mathrm{Ca}_{s w}-\mathrm{Ca}_{c f}\right)$, and the paracellular pathway, therefore, acts as a sink for calcium and not as a source as implicitly assumed in Gagnon et al. (2012). It thus follows that, to balance the loss via the paracellular pathway, active calcium transport, $F$, has to be larger than calcium incorporation into the skeleton, $P$ :

$$
P=F-0.6 \cdot k
$$

A similar calculation can be made for $\mathrm{pH}$ with the only difference that $\mathrm{CO}_{2}$ diffusion and subsequent $\mathrm{pH}$ changes by the carbonate chemistry have to be considered. The conclusion, however, remains the same: in order to keep the calcifying fluid $\mathrm{pH}$ elevated with respect to seawater (Al-Horani et al., 2003; Ries, 2011; McCulloch et al., 2012; Venn et al., 2013), the paracellular exchange must be very small.

The paracellular pathway is a passive leakage that counteracts the gradients of calcium, $\mathrm{pH}$, and carbonate ions that are established via the active transcellular transport. The transcellular transport accounts for $100.8 \%$ of the total net calcium flux 
because $0.8 \%$ of the net flux is lost via the paracellular passage (Figure 2). Despite calcium is lost, the paracellular pathway contributes up to $1.2 \%$ to the total carbon transport into the calcifying fluid (Figure 2), mainly in the form of bicarbonate (Table 2). Carbonate ion concentrations in the calcifying fluid are higher and bicarbonate concentrations are lower than in seawater. Consequently, carbonate ions leak out of the calcifying fluid while bicarbonate leaks in.

Increasing calcification rates with increasing seawater concentrations of carbonate and bicarbonate have led to the notion that corals use bicarbonate and carbonate for calcification (Comeau et al., 2012). Our results provide an alternative explanation and help to solve the long-lasting debate about the most likely carbon species used by corals to precipitate $\mathrm{CaCO}_{3}$ (Goreau, 1963; Pearse and Muscatine, 1971; Marubini and Atkinson, 1999; Furla et al., 2000; Allemand et al., 2011). While bicarbonate ions are transported actively and passively from seawater into the calcifying fluid, our model shows clearly that carbonate ions leaks out of the calcifying fluid. An increase of seawater carbonate concentrations, therefore, reduces the carbonate gradient between the calcifying fluid and seawater and thus reduces the leakage of carbonate from the calcifying fluid. Consequently, aragonite supersaturation in the calcifying fluid increases, favoring precipitation of aragonite. Ultimately, the precipitation of aragonite requires carbonate ions but, in the light of our findings, we argue that the origin of these is from the dissociation of carbonic acid and bicarbonate in the calcifying fluid rather than from seawater.

Note that we consider "net" fluxes here and that the paracellular pathway does allow seawater carbonate and other ions in seawater to enter the calcifying fluid (Cohen and McConnaughey, 2003; Cohen and Holcomb, 2009; Gagnon et al., 2012). However, the import of carbonate from seawater is accompanied by an even higher export of carbonate ions from the calcifying fluid, resulting in a net efflux. Since the paracellular exchange depends on the gradients between seawater and the calcifying fluid, the net flux can be positive for those ions (e.g., $\mathrm{Mg}^{2+}$ and $\mathrm{Sr}^{2+}$ ) whose concentrations are not biologically regulated in the calcifying fluid and are incorporated into the growing skeleton (Swart, 1981; Mitsuguchi et al., 1996; Marshall and McCulloch, 2002; Gaetani and Cohen, 2006). This possibility and radio-labeled calcium experiments (Tambutté et al., 1996) have led to the suggestion that also calcium can enter the calcifying fluid via this pathway (Tambutté et al., 2011, 2012; Gagnon et al., 2012). A careful analysis of the ion fluxes, however, clarifies that although seawater calcium may enter the calcifying fluid via the paracellular pathway, more calcium is lost to seawater, leading to a net calcium export from the calcifying fluid via this pathway (Figure 2). The paracellular pathway could only work as a net source for calcium if the concentration gradient would be directed into the calcifying fluid. But the only available data to date (Al-Horani et al., 2003) clearly indicate higher calcium concentrations in the calcifying fluid than in seawater.

Besides creating unique habitats that shelter a vast diversity of marine organisms (Moberg and Folke, 1999; Kleypas et al., 2005; Hoegh-Guldberg et al., 2007), coral skeletons provide information about ancient climates (Cohen et al., 2001; Cuif and Dauphin, 2005; Bohm et al., 2006; Gaetani et al., 2011; Tambutté et al., 2011). Skeletons formed at relatively high temperature are enriched in the lighter isotopes of carbon and oxygen and show higher incorporation of bivalent cations other than calcium (Mitsuguchi et al., 1996; Gaetani et al., 2011). These signals recorded in the coral skeletons are used as proxies for the growth conditions under which corals lived (Marshall and McCulloch, 2002; Meibom et al., 2006). Proxies are calibrated against observations from controlled laboratory experiments (Hönisch et al., 2004; Thiagarajan et al., 2011). However, these calibrations have shown that the isotopic fractionation and incorporation of bivalent cations deviate from abiotically precipitated aragonite, a phenomenon attributed to "vital effects" (Adkins et al., 2003; Sinclair, 2005; Meibom et al., 2006; Kuffner et al., 2012). Vital effects here describe every influence of the biological activity of the coral animal on the composition of the calcifying fluid.

Our results concerning the importance of the transcellular pathway and the active control of the ion composition of the calcifying fluid have implications for the understanding of vital effects on coral calcification (Hönisch et al., 2004; Meibom et al., 2006; Kuffner et al., 2012). As summarized in the ion flux budget (Table 2), our model suggests that the majority of carbon $(\sim 98 \%)$ enters the calcifying fluid via diffusion of metabolic $\mathrm{CO}_{2}$, while only $0.8 \%$ is transported actively as bicarbonate. These fluxes constrain the isotopic fractionation of carbon and oxygen in the coral skeleton since diffusion of $\mathrm{CO}_{2}$ generally favors the lighter isotopes over the heavier ones (O'Leary, 1984; McConnaughey, 1989). The low contribution of the paracellular pathway to the total calcium fluxes will influence the concentrations of magnesium and strontium relative to calcium and the incorporation of these into the coral skeleton. However, magnesium and strontium are not considered in the model, thus we cannot provide a quantification of their incorporation.

In absence of the paracellular pathway $(\mathrm{H} 1), \mathrm{CO}_{2}$ diffuses through the coral tissue and alters the carbonate chemistry in the calcifying fluid, leading to reduced calcification rates under increasing $\mathrm{pCO}_{2}$ (Figure 4A) as we reported previously (Hohn and Merico, 2012). The favoring of $\mathrm{H} 4$ over $\mathrm{H} 1$ as the most likely mechanism of coral calcification and the possibility that seawater is in contact with the calcifying fluid implies a direct and therefore more prominent impact of ocean acidification on the ability of corals to accrete carbonate. The difference in the calcification response to $\mathrm{pCO}_{2}$ between $\mathrm{H} 4$ and $\mathrm{H} 1$ is, however, marginal. The reduced seawater carbonate concentrations in H4 (Figure 4D) increase carbonate leakage from the calcifying fluid, while protons, bicarbonate and $\mathrm{CO}_{2}$ simultaneously leak in. However, the changes in the chemical composition of the calcifying fluid can be compensated for by the corals ability to control the transcellular ion transport by increasing the activity of the ion pump (Ries, 2011; McCulloch et al., 2012; Venn et al., 2013). But since active ion transport requires metabolic energy, coral resilience to ocean acidification will come at the cost of increasing energy demand via either heterotrophy or photosynthesis, a potential explanation for the productivity loss and the increased bleaching response of corals to ocean acidification (Anthony et al., 2008). 
The active transport of calcium may be expected to be energetically demanding since ATP is required to transport $\mathrm{Ca}^{2+}$ into the calcifying fluid $(\mathrm{H} 1+\mathrm{H} 4)$, whereas a passive diffusion of calcium through the paracellular pathway $(\mathrm{H} 2+\mathrm{H} 3+\mathrm{H} 4)$ would occur at no additional cost. There is however strong evidence, that active ion transport is present in the calicoblastic epithelium cells of scleractinian corals (Zoccola et al., 2004) and it appears plausible that the amount of energy required for calcification is fairly negligible with respect to the total metabolic requirements. Moreover, the energetic costs of the Ca-ATPase, which transports $2 \mathrm{Ca}^{2+}$ in exchange of $2-4 \mathrm{H}^{+}$while consuming one molecule of ATP per transport cycle (Inesi, 1985; Allemand et al., 2004; Winther et al., 2013), are in fact more beneficial for enhancing $\Omega_{\text {ara }}$ in the calcifying fluid than assuming a proton pump, which would transport $2-4 \mathrm{H}^{+}$per ATP alone (Bennett and Spanswick, 1984; Fillingame, 1997). The energy required to maintain the proton gradient between seawater and the calcifying fluid has been recently assessed using the Nernst potential (Jokiel, 2011; Ries, 2011). However, this approach calculates the "potential" energy between the two ends of the gradient and not the energy required to establish this gradient. The Nernst equation therefore underestimates the energetic costs of coral calcification. In addition, hydrolysis of ATP typically releases more energy than actually required by biochemical reactions such as active ion transport. The excess energy from hydrolysis is then dissipated as heat and thus lost. Other energy requiring processes by the calcification process such as those involving an organic matrix or carbonic anhydrase are not considered in this study.

We suggest that the observed resilience of the calcification process in corals to ocean acidification (McCulloch et al., 2012; Venn et al., 2013) is the consequence of the active control of the transcellular ion transport, whereas the passive paracellular leakage is the reason for its vulnerability (Fine and Tchernov, 2007). The relative contribution of both pathways to coral calcification may be a species-specific property, which may explain why different species appear to respond differently to ocean acidification (McCulloch et al., 2012). For example, the fact that massive corals such as Porites are found to thrive under high $\mathrm{pCO}_{2}$ conditions (Fabricius et al., 2011), could be explained by their compact geometry and, consequently, by a reduced paracellular leakage. Furthermore, septate junctions provide structural strength and a barrier to the diffusion of solutes through the intercellular space in vertebrate and invertebrate tissues and can thus potentially seal the calcifying fluid against seawater in corals (Ganot et al., 2014). A further indication that the paracellular exchange should be minimal is given by the fact that calicoblastic epithelium cells show lower proliferation rates (Lecointe et al., 2013) and therefore grow longer than cells of other coral epithelia (Allemand et al., 2004). Elongation of calicoblastic epithelium cells produces a lower areal fraction of the cell-to-cell boundaries that would be prone to the leakage of ions. Besides potential adaptations due to anatomic characteristics, the active regulation of the transcellular pathway offers corals a certain degree of plasticity to cope with increasing ocean acidity (e.g., Moya et al., 2012). How exactly the transcellular ion transport is regulated under varying environmental conditions remains to be determined.

\section{AUTHOR CONTRIBUTIONS}

Both authors conceived the ideas for this project and developed the model structure. Sönke Hohn coded the model and conducted the numerical analyses; both authors contributed to the interpretation of the results and to the writing of the manuscript.

\section{SUPPLEMENTARY MATERIAL}

The Supplementary Material for this article can be found online at: http://www.frontiersin.org/journal/10.3389/feart.2014.00037/ abstract

\section{REFERENCES}

Adkins, J. F., Boyle, E. A., Curry, W. B., and Lutringer, A. (2003). Stable isotopes in deep-sea corals and a new mechanism for Òvital effectsÓ. Geochimica et Cosmochimica 67, 1129-1143. doi: 10.1016/S0016-7037(02) 01203-6

Al-Horani, F., Al-Moghrabi, S., and De Beer, D. (2003). The mechanism of calcification and its relation to photosynthesis and respiration in the scleractinian coral Galaxea fascicularis. Mar. Biol. 142, 419-426. doi: 10.1007/s00227-0020981-8

Allemand, D., Ferrier-Pagès, C., Furla, P., Houlbrèque, F., Puverel, S., Reynaud, S. et al. (2004). Biomineralisation in reef-building corals: from molecular mechanisms to environmental control. C. R. Palevol. 3, 453-467. doi: 10.1016/j.crpv.2004.07.011

Allemand, D., Tambutté, E., Zoccola, D., and Tambutté, S. (2011). "Coral calcification, cells to reefs," in Coral Reefs: An Ecosystem in Transition, eds Z. Dubinsky and N. Stambler (Dordrecht; Heidelberg; London; New York: Springer), 119-150. doi: 10.1007/978-94-007-0114-4_9

Anthony, K. R. N., Kline, D. I., Diaz-Pulido, G., Dove, S. and Hoegh-Guldberg, O. (2008). Ocean acidification causes bleaching and productivity loss in coral reef builders. Proc Natl. Acad. Sci. U.S.A. 105, 17442-17446. doi: 10.1073/pnas.0804478105

Bennett, A., and Spanswick, R. (1984). $\mathrm{H}^{+}$-ATPase activity from storage tissue of beta vulgaris II. $\mathrm{H}^{+} /$ATP stoichiometry of an anion-sensitive $\mathrm{H}^{+}$-ATPase. Plant Physiol. 74, 545-548. doi: 10.1104/pp.74.3.545

Bergman, C., Kashiwaya, Y., and Veech, R. L. (2010). The effect of pH and free $\mathrm{Mg}^{2+}$ on ATP linked enzymes and the calculation of Gibbs free energy of ATP hydrolysis. J. Phys. Chem. B 114, 16137-16146. doi: 10.1021/ jp105723r

Bohm, F., Gussone, N., Eisenhauer, A., Dullo, W., Reynaud, S., and Paytan, A. (2006). Calcium isotope fractionation in modern scleractinian corals. Geochimica et Cosmochimica Acta 70, 4452-4462. doi: 10.1016/j.gca.2006.06.1546

Cohen, A. L., and Holcomb, M. (2009). Why corals care about ocean acidification: uncovering the mechanism. Oceanography 22, 118-127. doi: 10.5670/oceanog.2009.102

Cohen, A. L., Layne, G. D., Hart, S. R., and Lobel, P. S. (2001). Kinetic control of skeletal Sr/Ca in a symbiotic coral: implications for the paleotemperature proxy. Paleoceanography 16, 20-26. doi: 10.1029/1999PA000478

Cohen, A., and McConnaughey, T. (2003). Geochemical perspectives on coral mineralization. Rev. Mineral. Geochem. 54, 151-187. doi: 10.2113/ 0540151

Comeau, S., Carpenter, R. C., and Edmunds, P. J. (2012). Coral reef calcifiers buffer their response to ocean acidification using both bicarbonate and carbonate. Proc. R. Soc. B Biol. Sci. 280:20122374. doi: 10.1098/rspb. 2012.2374

Cuif, J. P., and Dauphin, Y. (2005). The environment recording unit in coral skeletons a synthesis of structural and chemical evidences for a biochemically driven, stepping-growth process in fibres. Biogeosciences 2, 61-73. doi: 10.5194/bg-2-61-2005

Cuif, J.-P., Dauphin, Y., and Sorauf, J. (2011). Biominerals and fossils Through Time. Cambridge: Cambridge University Press.

Fabricius, K. E., Langdon, C., Uthicke, S., Humphrey, C., Noonan, S., De'ath, G., et al. (2011). Losers and winners in coral reefs acclimatized to elevated 
carbon dioxide concentrations. Nat. Clim. Change 1, 165-169. doi: 10.1038/nclimate1122

Fillingame, R. H. (1997). Coupling $\mathrm{H}^{+}$transport and ATP synthesis in F1F0-ATP synthases: glimpses of interacting parts in a dynamic molecular machine. J. Exp. Biol. 200, 217-224.

Fine, M., and Tchernov, D. (2007). Scleractinian coral species survive and recover from decalcification. Science 315:1811. doi: 10.1126/science.1137094

Frankignoulle, M., Canon, C., and Gattuso, J. (1994). Marine calcification as a source of carbon dioxide: positive feedback of increasing atmospheric $\mathrm{CO}_{2}$. Limnol. Oceanogr. 39, 458-462. doi: 10.4319/lo.1994.39.2.0458

Furla, P., Galgani, I., and Durand, I. (2000). Sources and mechanisms of inorganic carbon transport for coral calcification and photosynthesis. J. Exp. Biol. 203, 3445-3457. Available online at: http://jeb.biologists.org/content/203/22/3445. abstract

Gaetani, G. A., Cohen, A. L., Wang, Z., and Crusius, J. (2011). Rayleighbased, multi-element coral thermometry: a biomineralization approach to developing climate proxies. Geochimica et Cosmochimica Acta 75, 1920-1932. doi: 10.1016/j.gca.2011.01.010

Gaetani, G., and Cohen, A. (2006). Element partitioning during precipitation of aragonite from seawater: a framework for understanding paleoproxies. Geochimica et Cosmochimica Acta 70, 4617-4634. doi: 10.1016/j.gca.2006. 07.008

Gagnon, A. C., Adkins, J. F., and Erez, J. (2012). Seawater transport during coral biomineralization. Earth Planet. Sci. Lett. 329-330, 150-161. doi 10.1016/j.epsl.2012.03.005

Ganot, P., Zoccola, D., Tambutté, E., Voolstra, C. R., Aranda, M., Allemand, D. et al. (2014). Structural molecular components of septate junctions in cnidarians point to the origin of epithelial junctions in eukaryotes. Mol. Biol. Evol. doi: 10.1093/molbev/msu265. [Epub ahead of print].

Goreau, T. F. (1963). Calcium carbonate deposition by coralline algae and corals in relation to their roles as reef-builders. Ann. N.Y. Acad. Sci. 109, 127-167. doi: 10.1111/j.1749-6632.1963.tb13465.x

Gould, G. W., East, J. M., Froud, R. J., McWhirter, J. M., Stefanova, H. I., and Lee, A. G. (1986). A kinetic model for the $\mathrm{Ca}^{2+}+\mathrm{Mg}^{2+}$-activated ATPase of sarcoplasmic reticulum. Biochem. J. 237, 217-227.

Hönisch, B., Hemming, N. G., Grottoli, A. G., Amat, A., Hanson, G. N., and Bijma, J. (2004). Assessing scleractinian corals as recorders for paleo-pH: empirical calibration and vital effects. Geochimica et Cosmochimica Acta 68, 3675-3685. doi: 10.1016/j.gca.2004.03.002

Hallock, P., (1997). "Reefs and reef limestones in earth history," in Life and Death of Coral Reefs, ed C. Birkeland (New York, NY: Chapman and Hall), 13-42.

Hoegh-Guldberg, O., Mumby, P. J., Hooten, A. J., Steneck, R. S., Greenfield, P., Gomez, E. et al. (2007). Coral reefs under rapid climate change and ocean acidification. Science 318, 1737-1742. doi: 10.1126/science.1152509

Hohn, S., and Merico, A. (2012). Modelling coral polyp calcification in relation to ocean acidification. Biogeosciences 9, 4441-4454. doi: 10.5194/bg-9-4441-2012

Inesi, G. (1985). Mechanism of calcium transport. Ann. Rev . Physiol. 47, 573-601. doi: 10.1146/annurev.ph.47.030185.003041

Ip, Y., Lim, A., and Lim, R. (1991). Some properties of calcium-activated adenosine triphosphatase from the hermatypic coral Galaxea fascicularis. Mar. Biol. 111, 191-197. doi: 10.1007/BF01319700

Jokiel, P. L. (2011). Ocean acidification and control of reef coral calcification by boundary layer limitation of proton flux. Bull. Mar. Sci. 87, 639-657. doi: 10.5343/bms.2010.1107

Kamerlin, S. C. L., and Warshel, A. (2009). On the energetics of ATP hydrolysis in solution. J. Phys. Chem. B 113, 15692-15698. doi: 10.1021/jp907223t

Kleypas, J., Buddemeier, R., and Gattuso, J.-P. (2001). The future of coral reefs in an age of global change. Int. J. Earth Sci. 90, 426-437. doi: 10.1007/s005310000125

Kleypas, J., Feely, R. A., Fabry, V. J., Langdon, C., Sabine, C. L., and Robbins, L. L. (2005). "Impacts of ocean acidification on coral reefs and other marine calcifiers: a guide for future research," In Report of a Workshop Held, Vol. 18 (St. Petersburg), 20.

Kuffner, I. B., Jokiel, P. L., Rodgers, K. S., Andersson, A. J., and Mackenzie, F. T. (2012). An apparent Òvital effectÓ of calcification rate on the Sr/Ca temperature proxy in the reef coral Montipora capitata. Geochem. Geophys. Geosys. 13:08004. doi: 10.1029/2012GC004128

Lecointe, A., Cohen, S., Gèze, M., Djediat, C., Meibom, A., and Domart-Coulon, I. (2013). Scleractinian coral cell proliferation is reduced in primary culture of suspended multicellular aggregates compared to polyps. Cytotechnology 65, 705-724. doi: 10.1007/s10616-013-9562-6

Lemasters, J. J. (1984). The ATP-to-Oxygen stoichiometries of oxidative phosphorylation by rat liver mitochondria. J. Biol. Chem. 259, 13123-13130.

Marshall, J., and McCulloch, M. (2002). An assessment of the Sr/Ca ratio in shallow water hermatypic corals as a proxy for sea surface temperature. Geochimica et Cosmochimica Acta 66, 3263-3280. doi: 10.1016/S0016-7037(02) 00926-2

Marubini, F., and Atkinson, M. (1999). Effects of lowered $\mathrm{pH}$ and elevated nitrate on coral calcification. Mar. Ecol. Prog. Ser. 188, 117-121. doi: $10.3354 /$ meps 188117

McConnaughey, T. (1989). 13C and 180 isotopic disequilibrium in biological carbonates: II. In vitro simulation of kinetic isotope effects. Geochimica et Cosmochimica Acta 53, 163-171.

McCulloch, M., Falter, J., Trotter, J., and Montagna, P. (2012) Coral resilience to ocean acidification and global warming through $\mathrm{pH}$ up-regulation. Nat. Clim. Change 2, 1-5. doi: 10.1038/nclimate1473

Meibom, A., Yurimoto, H., Cuif, J.-P., Domart-Coulon, I., Houlbreque, F., Constantz, B., et al. (2006). Vital effects in coral skeletal composition display strict three-dimensional control. Geophys. Res. Lett. 33:L11608. doi: 10.1029/2006GL025968

Mitsuguchi, T., Matsumoto, E., Abe, O., Uchida, T., and Isdale, P. (1996). Mg/Ca Thermometry in Coral Skeletons. Science 274, 961-963. doi: 10.1126/science.274.5289.961

Moberg, F., and Folke, C. (1999). Ecological goods and services of coral reef ecosystems. Ecol. Econ. 29, 215-233. doi: 10.1016/S0921-8009(99)00009-9

Moya, A., Huisman, L., Ball, E. E., Hayward, D. C., Grasso, L. C., Chua, C. M. et al. (2012). Whole transcriptome analysis of the coral Acropora millepora reveals complex responses to $\mathrm{CO} 2$-driven acidification during the initiation of calcification. Mol. Ecol. 21, 2440-2454. doi: 10.1111/j.1365-294X.2012. 05554.x

Nakamura, T., Nadaoka, K., and Watanabe, A. (2013). A coral polyp model of photosynthesis, respiration and calcification incorporating a transcellular ion transport mechanism. Coral Reefs 32, 779-794. doi: 10.1007/s00338-0131032-2

O'Leary, M. H. (1984). Measurement of the isotope fractionation associated with diffusion of carbon dioxide in aqueous solution. J. Phys. Chem. 88, 823-825.

Pearse, V., and Muscatine, L. (1971). Role of symbiotic algae (Zooxanthellae) in coral calcification. Biol. Bull. 141, 350-363. doi: 10.2307/1540123

Ries, J. B. (2011) A physicochemical framework for interpreting the biological calcification response to $\mathrm{CO}_{2}$-induced ocean acidification. Geochimica et Cosmochimica Acta 75, 4053-4064. doi: 10.1016/j.gca.2011.04.025

Sinclair, D. J. (2005). Correlated trace element Òvital effectsÓ in tropical corals: a new geochemical tool for probing biomineralization. Geochimica et Cosmochimica Acta 69 , 3265-3284. doi: 10.1016/j.gca.2005.02.030

Sueltemeyer, D. and Rinast, K.-A. (1996). The $\mathrm{CO}_{2}$ permeability of the plasma membrane of Chlamydomonas reinhardtii: mass-spectrometric ${ }^{18} \mathrm{O}$-exchange measurements from ${ }^{13} \mathrm{C}^{18} \mathrm{O}_{2}$ in suspensions of carbonic anhydrase-loaded plasma-membrane vesicles. Planta 200, 358-368.

Swart, P. (1981). The strontium, magnesium and sodium composition of recent scleractinian coral skeletons as standards for palaeoenvironmental analysis. Palaeogeogr. Palaeoclimatol. Palaeoecol. 34, 115-136. doi: 10.1016/00310182(81)90060-2

Tambutté, E., Allemand, D., Mueller, E., and Jaubert, J. (1996). A compartmental approach to the mechanism of calcification in hermatypic corals. J. Exp. Biol. 199, 1029-1041.

Tambutté, E., Tambutté, S., Segonds, N., Zoccola, D., Venn, A., Erez, J., et al. (2012). Calcein labelling and electrophysiology: insights on coral tissue permeability and calcification. Proc. R. Soc. B Biol. Sci. 279, 19-27. doi: 10.1098/rspb.2011.0733

Tambutté, S., Holcomb, M., Ferrier-Pagès, C., Reynaud, S., Tambutté, E., Zoccola, D., et al. (2011). Coral biomineralization: from the gene to the environment. $J$. Exp. Mar. Biol. Ecol. 408, 58-78. doi: 10.1016/j.jembe.2011.07.026

Thiagarajan, N., Adkins, J., and Eiler, J. (2011). Carbonate clumped isotope thermometry of deep-sea corals and implications for vital effects. Geochimica et Cosmochimica Acta 75, 4416-4425. doi: 10.1016/j.gca.2011.05.004

Venn, A., Tambutté, E., Holcomb, M., Laurent, J., Allemand, D., and Tambutté, S. (2013). Impact of seawater acidification on $\mathrm{pH}$ at the tissue-skeleton interface 
and calcification in reef corals. Proc. Natl. Acad. Sci. U.S.A. 110, 1634-1639. doi: $10.1073 /$ pnas. 1216153110

Vidal-Dupiol, J., Zoccola, D., Tambutté, E., Grunau, C., Cosseau, C., Smith, K. M., et al. (2013). Genes related to ion-transport and energy production are upregulated in response to $\mathrm{CO}_{2}$-driven $\mathrm{pH}$ decrease in corals: new insights from transcriptome analysis. PloS ONE 8:e58652. doi: 10.1371/journal.pone. 0058652

Ware, J., Smith, S., and Reaka-Kudla, M. (1992). Coral reefs: sources or sinks of atmospheric $\mathrm{CO}_{2}$ ? Coral Reefs 11, 127-130. doi: 10.1007/BF00255465

Winther, A.-M. L., Bublitz, M., Karlsen, J. L., Moeller, J. V., Hansen, J. B., Nissen, P., et al. (2013). The sarcolipin-bound calcium pump stabilizes calcium sites exposed to the cytoplasm. Nature 495, 265-269. doi: 10.1038/nature11900

Zeebe, R. E., and Wolf-Gladrow, D. A. (2001). $\mathrm{CO}_{2}$ in Seawater: Equilibrium, Kinetics, Isotopes, Vol. 65 of Elsevier Oceanography Book Series, 1st Edn. Amsterdam: Elsevier.

Zoccola, D., Tambutté, E., Failla, J.-P., Jaubert, J., and Allemand, D. (1999). Cloning of a calcium channel al subunit from the reef-building coral, Stylophora pistillata. Gene 227, 157-167. doi: 10.1016/S0378-1119(98)00602-7

Zoccola, D., Tambutté, E., Kulhanek, E., Puverel, S., Scimeca, J.-C., Allemand, D., et al. (2004). Molecular cloning and lLocalization of a PMCA P-type calcium
ATPase from the coral Stylophora pistillata. Biochimi. Biophys. Acta 1663, 117-126. doi: 10.1016/j.bbamem.2004.02.010

Conflict of Interest Statement: The authors declare that the research was conducted in the absence of any commercial or financial relationships that could be construed as a potential conflict of interest.

Received: 16 October 2014; paper pending published: 14 November 2014; accepted: 08 December 2014; published online: 07 January 2015.

Citation: Hohn S and Merico A (2015) Quantifying the relative importance of transcellular and paracellular ion transports to coral polyp calcification. Front. Earth Sci. 2:37. doi: 10.3389/feart.2014.00037

This article was submitted to Marine Biogeochemistry, a section of the journal Frontiers in Earth Science.

Copyright (c) 2015 Hohn and Merico. This is an open-access article distributed under the terms of the Creative Commons Attribution License (CC BY). The use, distribution or reproduction in other forums is permitted, provided the original author(s) or licensor are credited and that the original publication in this journal is cited, in accordance with accepted academic practice. No use, distribution or reproduction is permitted which does not comply with these terms. 